\title{
The Korean herbal formulation Yukmijihwangtang stimulates longitudinal bone growth in animal models
}

\author{
Sung-Min Cho ${ }^{1,2+}$, Sun Haeng Lee ${ }^{3 \dagger}$, Donghun Lee ${ }^{4}$, Ji Hong Lee ${ }^{1}$, Gyu Tae Chang ${ }^{1,5}$, Hocheol Kim*
} and Jin Yong Lee L $^{1, *^{*}}$

\begin{abstract}
Background: Yukmijihwangtang (YJT) is a traditional Korean medicine that has been used to treat kidney-yin deficiency symptoms such as dizziness and tinnitus. In addition, because it is also thought to nourish kidney-yin, it has been used to treat short stature from congenital deficiency. This study evaluated the effects of YJT on longitudinal bone growth in rats.

Methods: Female adolescent rats were randomly assigned to groups that received distilled water (per os [p.o.] twice a day; control), recombinant human growth hormone ( $\mathrm{rhGH} ; 20 \mu \mathrm{g} / \mathrm{kg}$, subcutaneous [s.c.] once a day), or two different doses of YJT (100 or 300 mg/kg, p.o. twice a day). In each group, treatment was maintained for 4 days. Rats were injected intraperitoneally with 5-bromo-2'-deoxyuridine (BrdU; $50 \mathrm{mg} / \mathrm{kg}$ ) to label proliferating chondrocytes on days 2 - 4. Tetracycline hydrochloride $(20 \mathrm{mg} / \mathrm{kg}$ ) was injected intraperitoneally to form fluorescent bands on the growth plates on day 3 for measuring the longitudinal bone growth rate. Expression of insulin-like growth factor-1 (IGF-1) and bone morphogenetic protein-2 (BMP-2) in the growth plate was identified using immunohistochemistry.

Results: There was a significant increase in the rate of bone growth in the $300 \mathrm{mg} / \mathrm{kg} \mathrm{YJT}$ group $(523.8 \pm 23.7 \mu \mathrm{m} /$ day; $P<0.05)$ compared to the control group $(498.0 \pm 23.8 \mu \mathrm{m} /$ day), while the $100 \mathrm{mg} / \mathrm{kg} \mathrm{YJT}$ group exhibited a non-significant increase. The number of BrdU-positive cells in the chondrocytes of the rhGH-treated group exhibited a significant increase $\left(103.8 \pm 34.2 \mathrm{cells} / \mathrm{mm}^{2}\right)$ compared to that of the control group $\left(70.3 \pm 19.7 \mathrm{cell} / \mathrm{s} / \mathrm{mm}^{2}\right)$, while the $300 \mathrm{mg} / \mathrm{kg}$ YJT group had a non-significant increase. Additionally, IGF-1 and BMP-2 were highly expressed in the growth plate in the $300 \mathrm{mg} / \mathrm{kg}$ YJT and rhGH groups.

Conclusions: YJT increased the longitudinal bone growth rate by stimulating chondrocyte proliferation with increasing increments of local IGF-1 and BMP-2 expression. Based on these findings, YJT may be a therapeutic candidate for the treatment of growth retardation during adolescence.
\end{abstract}

Keywords: Yukmijihwangtang, Growth plate, Longitudinal bone growth, Recombinant human growth hormone

\section{Background}

Yukmijihwangtang (YJT) contains six medicinal herbs: Rehmannia glutinosa, Cornus officinalis, Dioscorea batatas, Alisma orientale, Poria cocos, and Paeonia suffruticosa. YJT has previously been prescribed to treat cancer, dementia, diabetes, hypertension, menopausal syndromes,

\footnotetext{
* Correspondence: hckim@khu.ac.kr; yjyee2080@hanmail.net

${ }^{\dagger}$ Equal contributors

${ }^{4}$ Department of Herbal Pharmacology, College of Korean Medicine, Kyung Hee University, Seoul 02447, Republic of Korea

'Department of Clinical Korean Medicine, Graduate School, Kyung Hee University, Seoul 02447, Republic of Korea

Full list of author information is available at the end of the article
}

nephritis, neurasthenia, neurosis, Parkinson's disease, systemic lupus erythematosus, and thrombocytopenic purpura. YJT possesses anti-aging, anti-carcinogenic, anti-hypertensive, anti-inflammatory, anti-osteoporotic, anti-oxidant and neuromodulating pharmacological effects. Therefore, administration of YJT is thought to delay declines in learning and memory, diminish the aging process and geriatric diseases, and strengthen estrogenic activity during menopause. Additionally, YJT has been used to treat clinical kidney-yin deficiency symptoms such as dizziness, hectic fever, dry mouth and throat, night sweats, spermatorrhea, excessive 
thirst and liquid intake, red tongue with less coating, and rapid pulse [1]. Previous experimental studies have shown that YJT enhances immune function by regulating the secretion of neurotransmitters and hormones associated with the hypothalamus-pituitary-adrenal axis [2], as well as strengthening bone by stimulating the remodeling process [3]. YJT also increases cognitive function via improvements in synaptic plasticity [4] and protects against neurodegeneration by adjusting mitochondrial function and downregulating apoptosis signals [5]. In a model of obesity, YJT improved energy metabolism and sensitivity to insulin and leptin, which, in turn, inhibited weight gain and visceral fat accumulation $[6,7]$. Additionally, YJT decreased prostate enlargement in a model of prostatic hyperplasia [8]. A previous clinical study found that YJT effectively improves hyperglycemia and renal function, while adverse events from the treatment were infrequent or mild [9].

Many herbal medicines have been evaluated to determine whether they promote skeletal growth. For example, Bojungikki-tang [10], Cheunggyeongsamul-tang [11], and Jaoga-yukmiwon [12] increased bone growth. It is expected that YJT will also promote bone growth, as the method of nourishing the kidney-yin has been used clinically on short statured patients with congenital deficiencies in Korea [13], and this compound is similar to the growth-promoting Jaoga-yukmiwon medicine; furthermore, YJT in conjunction with $\mathrm{Zi} \mathrm{He}$ Che (Hominis placenta) suppresses bone resorption [14]. However, non-significant differences in X-ray measurements of femur and tibia length following YJT treatment were observed previously, even though YJT increased serum levels of growth hormone $(\mathrm{GH})$ and thyroid hormones compared with the control group [15].

Due to the contradictory reports regarding the effect of YJT on bone growth, the present study evaluated the effects of two different concentrations of YJT in adolescent female rats. YJT doses of 100 and $300 \mathrm{mg} / \mathrm{kg}$ were used because these concentrations had significant effects on bone growth compared to a control group in a previous experiment that investigated adolescent female rats [10]. These two concentrations were less than a daily dose of $2.4 \mathrm{~g} / \mathrm{d}$, which was converted from the recommended clinical daily dose of $4.5 \mathrm{~g} / \mathrm{d}$ in humans [16], and were expected to have few side effects. Additionally, one group of rats in the present study received $\mathrm{GH}$ as a positive control, because GH affects final height after birth and plays a variety of roles during the growth spurt in adolescence [17]; furthermore, over-expression of the GH gene in rats significantly increases the growth of the body and organs [18]. However, it has also been shown that administration of $\mathrm{GH}$ to prepubertal rats promotes tibial growth and weight increases (in females but not in males) [19]. Therefore, adolescent female rats were used as the experimental animals in the present study and tibial growth was assessed because height is more related to the lower extremities than the upper extremities [20]. Furthermore, with respect to the lower limbs, tibia length is the best indicator of height [21].

In this study, longitudinal bone growth was determined by evaluating increases in the length of the tibial growth plate over $48 \mathrm{~h}$. To accomplish this, the number of 5-bromo-2'-deoxyuridine (BrdU)-positive cells in the growth plate was determined to verify cartilage proliferation, and immunohistochemistry was applied to assess the expression of bone morphogenetic protein-2 (BMP2) and insulin-like growth factor-1 (IGF-1), which are involved in bone growth in the growth plate [22].

\section{Methods}

\section{Sample preparation}

Radix Rehmanniae Prepara, Corni Fructus, Dioscoreae Rhizoma, Alismatis Rhizoma, Poria, and Moutan Cortex were purchased from Yaksoodang (Seoul, Korea). They were identified by Professor Hocheol Kim and voucher specimens (Nos. 14032809, 14032807, 14032808, 14032812, 14032806, and 14032805, respectively) were deposited in the Department of Herbal Pharmacology (College of Korean Medicine) of Kyung Hee University (Seoul, Korea).

The prepared root of $R$. glutinosa, fruit of C. officinalis, rhizomes of $D$. batatas and $A$. orientale, scleorotia of $P$. cocos, and root bark of $P$. suffruticosa were mixed at a ratio of $4: 2: 2: 1: 1: 1$, which is similar to the ratio $(8: 4: 4: 3: 3: 3)$ described in Qian Yi's ancient book "Key to Therapeutics of Children's Disease" [23], and was extracted with distilled water twice for $4 \mathrm{~h}$ at $100{ }^{\circ} \mathrm{C}$ in a reflux apparatus (Table 1). The extracts were filtrated and concentrated under reduced pressure and the samples were lyophilized to yield powders; the yield of the extract was $72.7 \%$.

The quantitative authentication of YJT was performed on Waters instrument (Milford, MA, USA) equipped with a Waters 1525 pump, Waters 2707 autosampler, and a Waters 2998 PDA detector using a Sunfire ${ }^{\mathrm{m}}$ Octadecyl silyl silica C18 column (particle size, $5 \mu \mathrm{m}$; $250 \times 4.6 \mathrm{~mm}$ ). The column was equilibrated with distilled water (solvent $\mathrm{A}$ ) and $50 \% \mathrm{MeOH}$ (solvent $\mathrm{B}$ ) at a flow rate of $1.0 \mathrm{~mL} / \mathrm{min}$. The column was eluted as

Table 1 Composition of Yukmijihwangtang

\begin{tabular}{|c|c|c|c|}
\hline Herbal name & Plant name & $\begin{array}{l}\text { Plant part } \\
\text { utilized }\end{array}$ & Amount (g) \\
\hline $\begin{array}{l}\text { Radix Rehmanniae } \\
\text { Prepara }\end{array}$ & Rehmannia glutinosa & Prepared root & 36.4 \\
\hline Corni Fructus & Cornus officinalis & Fruit & 18.2 \\
\hline Dioscoreae Rhizoma & Dioscorea batatas & Rhizomes & 18.2 \\
\hline Alismatis Rhizoma & Alisma orientale & Rhizomes & 9.1 \\
\hline Poria & Poria cocos & Scleorotia & 9.1 \\
\hline Moutan Cortex & Paeonia suffruticosa & Root bark & 9.1 \\
\hline
\end{tabular}


follows: $0-30 \mathrm{~min}, 20 \%$ solvent $\mathrm{B} ; 31-40 \mathrm{~min}, 60 \%$ solvent B; $41-55 \mathrm{~min}, 75 \%$ solvent B; $55-60 \mathrm{~min}, 60 \%$ solvent B; 60-65 min, 20\% solvent B. The highperformance liquid chromatogram of YJT is shown in Fig. 1. YJT contained two representative components: $8.71 \mathrm{mg} / \mathrm{mL}$ of 5-hydroxymethyl-2-furaldahyde for $R$. glutinosa and $4.19 \mathrm{mg} / \mathrm{mL}$ of paeoniflorin for $P$. suffruticosa.

\section{Animals and administration}

This study included 32 female Sprague-Dawley rats (4-weeks-old) that weighed $70 \pm 10 \mathrm{~g}$ each (Samtako Co., Osan, Korea). All experimental procedures were performed in accordance with the animal care guidelines of the Kyung Hee University's Institutional Animal Care and Use Committee (KHUASP (SE)-10-034). The 3weeks-old animals divided by four body weight groups (30-40 g, 40-50 g, 50-60 g, and 60-70 g). They were randomly put in the eight cages (4 rats/cage) by way of uniform weight distribution and the four treatments were assigned to the randomized cages. The animals were housed under controlled conditions (temperature of $23 \pm 2{ }^{\circ} \mathrm{C}$, relative humidity of $55 \pm 10 \%$; 07:00-19:00 light cycle with food and water available ad libitum). After 5 days of acclimatization, the treatments were maintained for 4 consecutive days in each group. The control group received oral administrations of distilled water twice a day, the positive control group was subcutaneously injected with $20 \mu \mathrm{g} / \mathrm{kg}$ of recombinant human GH (rhGH; LG Life Science, Daejeon, Korea) once a day, and the two YJT groups received oral administrations of either 100 or $300 \mathrm{mg} / \mathrm{kg}$, twice a day. Oral administration occurred at 09:00 and 21:00, and injections were performed at 09:00. All of the administrations were done in the home cage. After treatment, the animals were sacrificed prior to analysis.

\section{Measurement of longitudinal bone growth}

To investigate the effects of YJT on longitudinal bone growth, tetracycline was used as a fluorescence marker to label the bone line on the surface of the tibia; tetracycline is fluorescent under ultraviolet illumination. The rate of longitudinal bone growth was assessed by measuring the distance between the fluorescent line formed by tetracycline and the epiphyseal end line of the growth plate. To accomplish this, all rats received intraperitoneal (i.p.) injections of tetracycline hydrochloride $(20 \mathrm{mg} / \mathrm{kg}$; Sigma Chemicals Co., St. Louis, MO, USA) on day 3 of the experiment. On days 2-4, the rats received i.p. injections of BrdU (50 mg/kg, Sigma) to label proliferating cells, and on day 5 all animals were anesthetized with ether and sacrificed. The dissected tibias were fixed in $4 \%$ paraformaldehyde for $48 \mathrm{~h}$ and then underwent decalcification by immersion in a $10 \%$ ethylene diamine tetra acetic acid solution (Sigma) for $24 \mathrm{~h}$. After dehydration by immersion in a $30 \%$ sucrose solution for

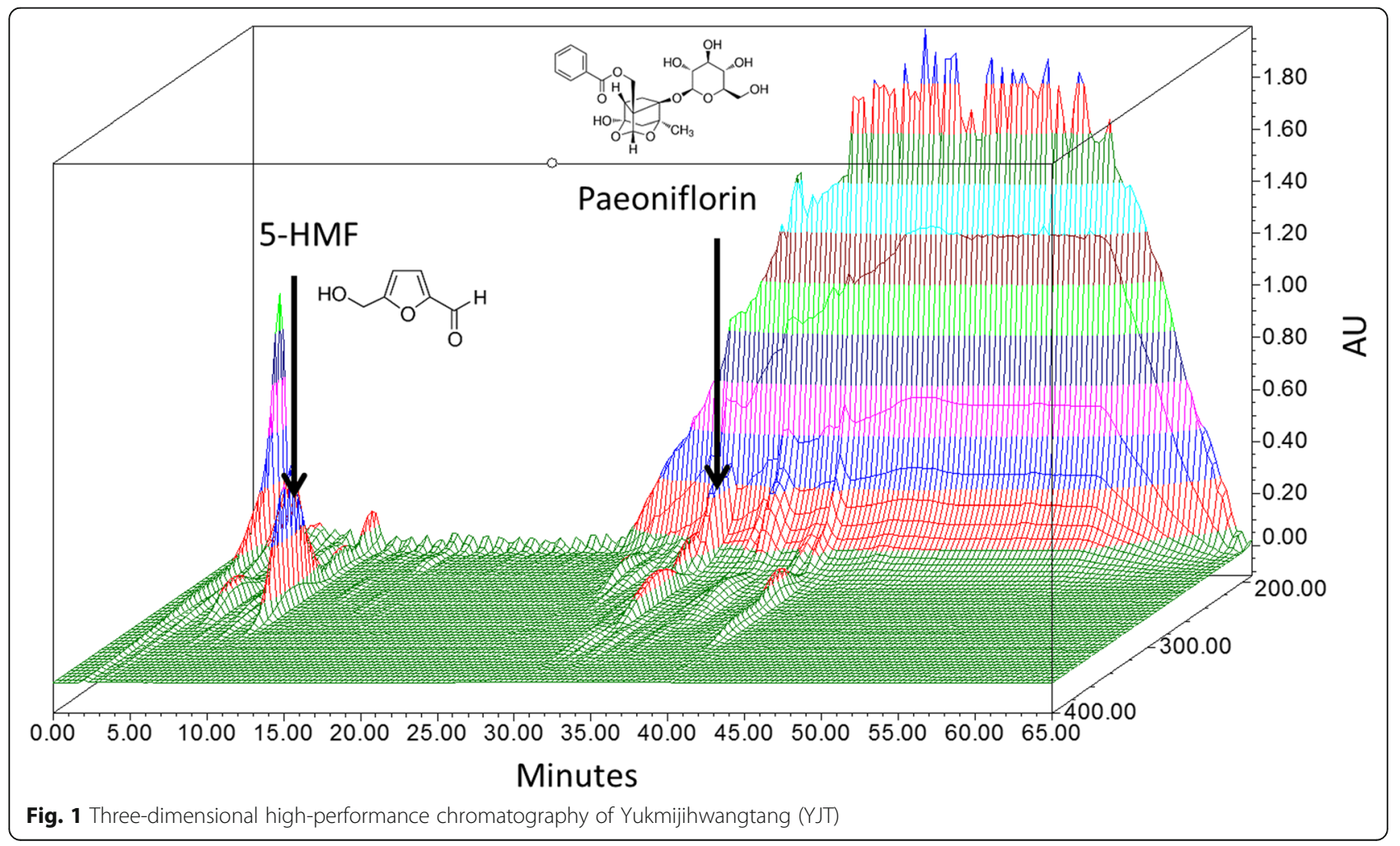




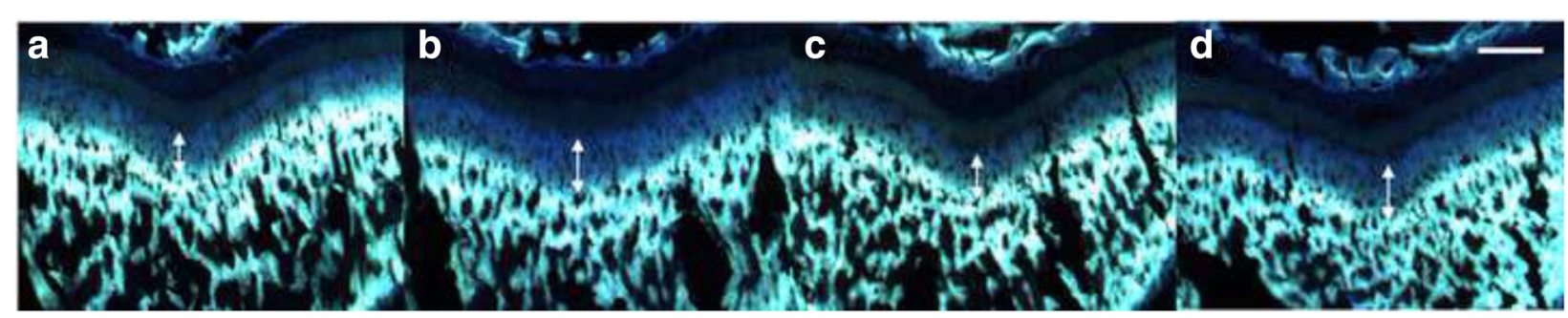

Fig. 2 Fluorescent photomicrographs of longitudinal sections of the proximal tibia in the growth plate. a Control group (distilled water), b recombinant human growth hormone $(\mathrm{rhGH})$ group $(20 \mathrm{\mu g} / \mathrm{kg})$, c $100 \mathrm{mg} / \mathrm{kg}$ YJT group, and $\mathbf{d} 300 \mathrm{mg} / \mathrm{kg}$ YJT group. The fluorescent line corresponds to the injection of tetracycline, which binds with calcium and can be detected with ultraviolet illumination. The arrow between the fluorescent line formed by the tetracycline and the epiphyseal end line of the growth plate indicates the extent of bone growth during the $48 \mathrm{~h}$ study period. Scale bar $=200 \mu \mathrm{m}$

1 day, each bone sample was longitudinally sectioned (40 $\mu \mathrm{m}$ thick) using a sliding microtome (HM440E; Carl Zeiss, Oberkochen, Germany). The focus was placed between the epiphyseal plate and the fluorescent band that was formed by the chelation of tetracycline and calcium on the epiphyseal plate following injection of tetracycline, which was visible under a fluorescence microscope (Olympus, Tokyo, Japan). Measurements and calculations of bone growth were performed using ImageJ software (National Institutes of Health, Bethesda, MD, USA) and mean values were obtained from three different sections within the fluorescent band gap.

\section{Measurement of BMP-2 and IGF-1 in the growth plate}

The tissue sections were washed twice in $0.1 \mathrm{M}$ phosphatebuffered saline (PBS), twice in 1\% triton X-100 (Sigma) for $15 \mathrm{~min}$, and then twice with $0.5 \%$ bovine serum albumin (BSA; Sigma) dissolved in PBS for 15 min. The sections were then incubated with goat BMP-2 primary antibody and rabbit IGF-1 primary antibody (1:200; Santa Cruz Biotechnology, Santa Cruz, CA, USA) overnight at room temperature in a humidity chamber. After $24 \mathrm{~h}$, the sections were washed twice with $0.5 \%$ BSA in PBS and then incubated with either biotinylated anti-goat secondary antibody (1:200; Vector Laboratories, Burlingame, CA, USA) or biotinylated anti-rabbit secondary antibody (1:200;

Table 2 Longitudinal bone growth rate in adolescent female rats

\begin{tabular}{ll}
\hline Group & $\begin{array}{l}\text { Longitudinal bone growth } \\
(\mu \mathrm{m} / \text { day })\end{array}$ \\
\hline Control & $498.0 \pm 23.8$ \\
Recombinant human growth hormone & $536.3 \pm 34.7^{*}$ \\
$(20 \mu \mathrm{g} / \mathrm{kg})$ & \\
Yukmijihwangtang (100 mg/kg) & $506.4 \pm 32.9$ \\
Yukmijihwangtang (300 mg/kg) & $523.8 \pm 23.7^{*}$ \\
\hline
\end{tabular}

The control group received distilled water. Values are means \pm SD of eight rats. Statistical significance was determined with a $t$-test: ${ }^{*} P<0.05$ compared to the control group
Jackson Immuno Research Laboratories, West Grove, PA, USA) for $1 \mathrm{~h}$. After being washed twice with PBS for $15 \mathrm{~min}$, the sections were incubated with an avidin-biotinperoxidase complex (1:100, Vectastain ABC Kit; Vector Laboratories) for $1 \mathrm{~h}$ at room temperature. After another wash with PBS, the sections were stained and reacted with a $0.05 \%$ 3, 3-diaminobenzidine (DAB) solution containing hydrogen peroxide in PBS. The reaction was stopped by washing them with $\mathrm{PBS}$ and then the slides were dehydrated with solutions of 50, 75, 95, and 100\% ethanol and xylene, in that order. The sections were mounted on glass slides with Permount medium solution (Fisher Scientific, Waltham, MA, USA) and micrographs of the sections were taken.

\section{Statistical analysis}

All data are presented as means \pm standard deviation (SD). The effects of the different treatments were compared by Student's $t$-test using GraphPad Prism 5 software (GraphPad Software Inc., San Diego, CA, USA); $P$ values $<0.05$ were considered to be statistically significant.

\section{Results}

Effects of YJT on the rate of longitudinal bone growth The effects of YJT on bone growth were assessed by taking measurements of the gap between the growth plate and the band formed by tetracycline at three different locations to obtain an average value (Fig. 2). Next, the extent of bone growth over $48 \mathrm{~h}$ was converted to a daily growth rate. There was a significant acceleration of longitudinal bone growth in the $300 \mathrm{mg} / \mathrm{kg}$ YJT and rhGH groups compared to the control group (Table 2, Fig. 3). However, there was no significant difference in the rate of bone growth between the $100 \mathrm{mg} / \mathrm{kg}$ YJT group and the control group.

\section{Effects of YJT on chondrocyte proliferation}

BrdU-labeled cells were observed in the chondrocytes (Fig. 4). The number of BrdU-positive cells in the rhGH group was significantly higher than that in the control group, but the number of BrdU-positive cells in the 


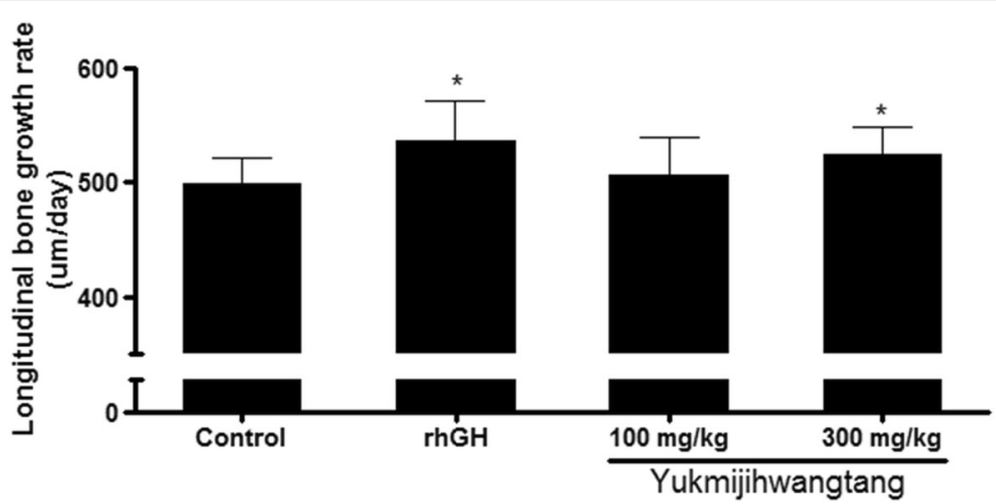

Fig. 3 Effects of YJT on longitudinal bone growth rate in adolescent rats. The control group: received distilled water and the rhGH group received $20 \mu \mathrm{g} / \mathrm{kg} \mathrm{rhGH}$. Values are means \pm SD of eight rats. ${ }^{*} P<0.05$ compared to the control group

$300 \mathrm{mg} / \mathrm{kg}$ YJT group did not significantly differ from that in the control group (Table 3, Fig. 5).

\section{Effects of YJT on the expression of BMP-2 and IGF-1}

Immunohistochemical experiments were conducted to evaluate the expression of BMP-2 and IGF-1 in the three principle zones of the growth plate. In all groups, the largest changes in BMP-2 and IGF-1 staining were evident in the cytoplasm of the proliferative and hypertrophic zones. Treatment with $300 \mathrm{mg} / \mathrm{kg}$ YJT markedly increased the expression of BMP-2 and IGF-1 in the proliferative zone and hypertrophic zone of the growth plate compared to treatment with distilled water. Additionally, expression of BMP-2 and IGF-1 was higher in the rhGH group than in the control and YJT groups (Fig. 6).

\section{Discussion}

In the present study, oral administration of YJT for 4 days significantly increased the rate of longitudinal bone growth and chondrocyte proliferation in the proximal tibial growth plate compared to the control group.
YJT also increased the expression of IGF-1 and BMP-2 in the hypertrophic zone of the growth plate.

A study that measured changes in bone length and serum hormone levels after YJT treatment found that this herbal medicine increased the levels of GH and thyroid hormone, but did not affect bone length or body weight [15]. In the $300 \mathrm{mg} / \mathrm{kg}$ YJT group in the present study, there was an increase in the rate of bone growth of $5.2 \%$ relative to the control group. Tetracycline accumulates in newly formed bone and produces fluorescent lines subsequent to its injection. The gap between the fluorescent line and the chondro-osseous junction indexes the rate of bone growth rate [24]. Using this procedure, the present study found that a higher dose of YJT increased the rate of bone growth. However, there was a non-significant increase in bone growth rate in the $100 \mathrm{mg} / \mathrm{kg}$ YJT group, which suggests that a certain concentration of YJT is required to significantly promote longitudinal bone growth. The 10-fold dose of YJT used in a previous study [15] might be an inappropriate dose for stimulating bone growth. Further study will be necessary to identify the most effective concentration for bone growth.

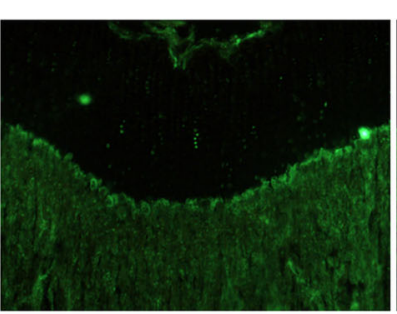

Control

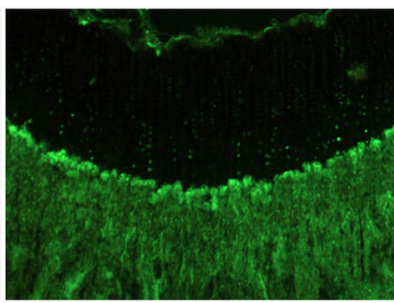

rhGH

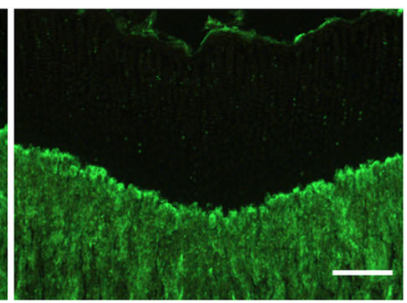

Yukmijihwangtang

Fig. 4 Representative images of 5-bromo-2'-deoxyuridine (BrdU)-labeled chondrocytes in the growth plates in the proximal tibia. The control group received distilled water, the $\mathrm{rhGH}$ group received $20 \mu \mathrm{g} / \mathrm{kg} \mathrm{rhGH}$ and the YJT group received $300 \mathrm{mg} / \mathrm{kg}$ YJT. Green: BrdU-labeled chondrocyte. Scale bar $=100 \mu \mathrm{m}$ 
Table 3 Numbers of BrdU-positive cells in the growth plate

\begin{tabular}{ll}
\hline Group & BrdU-positive cells $/ \mathrm{mm}^{2}$ \\
\hline Control & $70.3 \pm 19.7$ \\
$\begin{array}{l}\text { Recombinant human growth hormone } \\
(20 \mu \mathrm{g} / \mathrm{kg})\end{array}$ & $103.8 \pm 34.2^{*}$ \\
Yukmijihwangtang (300 mg/kg) & $93.8 \pm 22.0$ \\
\hline
\end{tabular}

The control group received distilled water. Values are means \pm SD of eight rats. Statistical significance was determined with a $t$-test: ${ }^{*} P<0.05$ compared to the control group

The growth plate matures due to the influences of various growth factors and hormones until late adolescence. The perichondrium, which is a key factor during growth plate maturation, plays an important role in osteoblast formation and capillary penetration [25]. Additionally, perichondrium cells regulate chondrocytes via BMPs, fibroblast growth factors, and Wnt signals. BMPs belong to the transforming growth factor (TGF) $\beta$ family and act as a growth and differentiation factor [26]. They determine chondrogenesis in pro-chondrogenic cells, accelerate the condensation process and differentiation into chondroblasts and chondrocytes, and aid in the formation of bone tissue [27, 28]. BMP-2 was selected as an indicator of bone growth in the present study because TGF- $\beta$ is unable to generate all types of bone tissue by itself, whereas BMP-2 alone induces ectopic bone formation [29]. BMP-2 also regulates the retinoid pathway, which causes chondrocyte proliferation [30], and promotes bone formation via the suppression of noggin, which inhibits bone tissue generation [31]. BMP-2 also accelerates bone growth by promoting chondrocyte proliferation and hypertrophy [32]. GH stimulates local-acting IGF-1 [33], which, as an essential growth-promoting polypeptide during normal bone metabolism, aids biosynthesis and substrate production in association with insulin-like anabolism [34, 35]. As a result, longitudinal bone growth is stimulated through chondrocyte proliferation and hypertrophy. IGF-1 was selected as another indicator of bone growth in the present study, because the heights of proliferative and hypertrophic zones in chondrocytes decrease under conditions of deficient IGF-1 [36].

The growth plate consists of a resting zone that contains immature cells, a proliferative zone that involves mature chondrocytes, and a hypertrophic zone that is comprised of enlarged chondrocytes [25]. The preparatory process for proliferation, in which progenitor cells are aligned in a parallel direction along the long axis of the bone, occurs in the resting zone [37]. During this process, flattened chondrocytes divide in the longitudinal direction and synthesize extracellular substrates that are essential for the cartilage matrix structure in the proliferative zone. Mineralization is accomplished by the secretion of large amounts of substrate protein, as well as by increases in the intracellular calcium concentration in the hypertrophic zone [22]. In the present study, the expression of BMP-2 and IGF-1 markedly increased in the proliferative and hypertrophic zones in the YJT groups, which suggests that YJT stimulated longitudinal bone growth by chondrocyte proliferation and hypertrophy in these areas. These results are similar to others obtained with bone growthpromoting herbal prescriptions.

Longitudinal bone growth appears to be a complex process that involves the proliferation and longitudinal hypertrophy of chondrocytes and the production of bone matrix. BrdU is a thymidine analog that bonds to $\mathrm{S}$ phase cells; thus, BrdU-labeled cells can be measured to confirm chondrocyte proliferation in the growth plate [38]. In the present study, the rhGH and YJT groups showed 1.5- and 1.3-fold increases in BrdUpositive cells, respectively, compared to the control group. However, while rhGH treatment resulted in a significant increase in BrdU-positive cells, YJT caused a non-significant increase. Therefore, the growth-promoting effects of YJT might be properly explained by other growth mechanisms.

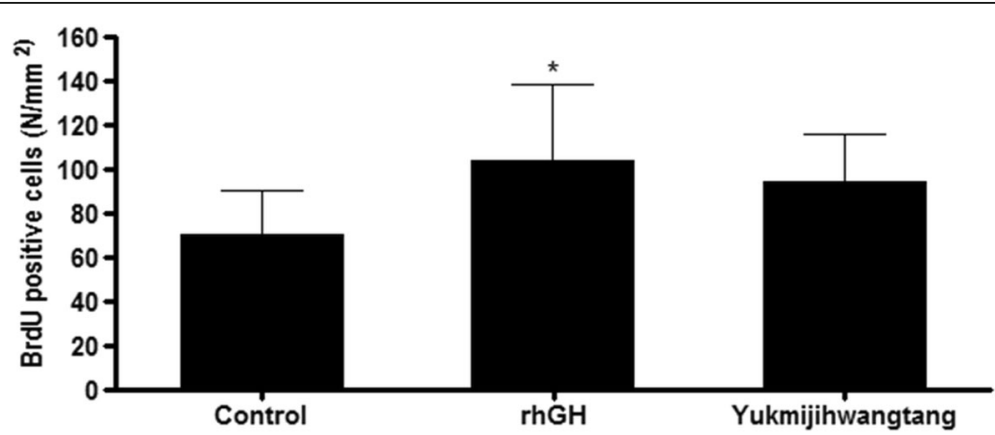

Fig. 5 Effects of YJT on chondrocyte proliferation in the growth plates of adolescent female rats. BrdU-positive cells were quantified. The control group received distilled water, the rhGH group received $20 \mu \mathrm{g} / \mathrm{kg} \mathrm{rhGH}$ and the YJT group received $300 \mathrm{mg} / \mathrm{kg}$ YJT. Values are means \pm SD of eight rats. ${ }^{*} P<0.05$ compared with the control group 


\begin{tabular}{l}
\hline Control \\
\hline
\end{tabular}

Diosgenin, a steroid saponin organizing Dioscorea, increases bone formation by enhancing the synthesis and secretion of Type 1 collagen and alkaline phosphate. Expression of bone marker proteins, Runx2 and osteopontin, stimulated by diosgenin also enhances calcium deposits within the extracellular matrix of bone [39]. Alisol-B, a steroid from A. orientale, suppresses osteoclastogenesis and prevents bone loss [40]. The bone growth-promoting effect of YJT might be due to enhancement of the extracellular matrix or prevention of bone loss. Further studies are needed to investigate these potential mechanisms.

In the present study, a large concentration of YJT produced a bone growth effect, but the induced growth was still less than that induced by rhGH, which is the approved treatment for idiopathic short stature [41]. However, long-term GH treatment is expensive and the ultimate height increase may still be small if the treated child does not have a GH deficiency [42]. GH treatment is generally safe but its long-term safety has yet to be confirmed and rare adverse effects, such as edema, pseudotumor cerebri, gynecomastia, hyperinsulinemia, and hyperglycemia, have been described [43]. The present findings suggest that YJT may be an alternative treatment for short stature that does not have the high cost or potential risks associated with $\mathrm{GH}$ treatment.

\section{Conclusions}

The present study demonstrated that at certain concentrations, YJT promotes longitudinal bone growth velocity via increases in the expression of BMP-2 and IGF-1 in the proliferative and hypertrophic zones of the growth plate. Although YJT has the potential to be a cost-effective and safe treatment for short stature, further studies are needed to verify the active components of this herbal medicine.

\section{Abbreviations}

BMP: Bone morphogenetic protein; BSA: Bovine serum albumin; GH: Growth hormone; IGF: Insulin-like growth factor; PBS: Phosphate-buffered saline; rhGH: Recombinant human growth hormone; YJT: Yukmijihwangtang

\section{Acknowledgements \\ This study was supported by a grant from the Korean Health Technology R\&D Project, Ministry of Health \& Welfare, Republic of Korea (HI14C0976).}

\section{Funding \\ None.}

Availability of data and materials

All data are presented within the manuscript.

\section{Author contributions}

SMC carried out the experiments and wrote the manuscript; SHL analyzed the data and wrote the manuscript; DL provided technical support for the experiments and revised the experiment protocol; JHL and GTC developed the experiment protocol and reviewed the manuscript; and HK and JYL approved the overall experimental design. All authors read and approved the final manuscript.

\section{Competing interests}

The authors declare that they have no competing interests.

\section{Consent for publication}

Not applicable.

\section{Ethics approval and consent to participate}

Ethics approval was obtained from Kyung Hee University's Institutional Animal Care and Use Committee (KHUASP (SE)-10-034).

\section{Author details}

${ }^{1}$ Department of Clinical Korean Medicine, Graduate School, Kyung Hee University, Seoul 02447, Republic of Korea. ${ }^{2} \mathrm{KHI}$ Oriental Clinic for Children, Gyeonggi 18455, Republic of Korea. ${ }^{3}$ Department of Pediatrics of Korean Medicine, Kyung Hee University Korean Medicine Hospital, Kyung Hee University Medical Center, Seoul 02447, Republic of Korea. ${ }^{4}$ Department of Herbal Pharmacology, College of Korean Medicine, Kyung Hee University, Seoul 02447, Republic of Korea. ${ }^{5}$ Department of Pediatrics of Korean Medicine, Kyung Hee University Hospital at Gangdong, Seoul 05278, Republic of Korea. 
Received: 10 October 2016 Accepted: 23 February 2017 Published online: 02 May 2017

\section{References}

1. Yuhong H, Qian L, Yu L, Yingqiang Z, Yanfen L, Shujing Y, Shufang Q, Lanjun S, Shuxuan Z, Baohe W. An n-of-1 trial service in clinical practice: testing the effectiveness of liuwei dihuang decoction for kidney-Yin deficiency syndrome. Evid Based Complement Alternat Med. 2013;2013:827915.

2. Zhou W, Cheng X, Zhang Y. Effect of liuwei dihuang decoction, a traditional Chinese medicinal prescription, on the neuroendocrine immunomodulation network. Pharmacol Ther. 2016;162:170-8.

3. Xia B, Xu B, Sun Y, Xiao L, Pan J, Jin H, Tong P. The effects of liuwei dihuang on canonical Wnt/beta-catenin signaling pathway in osteoporosis. J Ethnopharmacol. 2014;153(1):133-41.

4. Huang Y, Zhang H, Yang S, Qiao H, Zhou W, Zhang Y. Liuwei Dihuang decoction facilitates the induction of long-term potentiation (LTP) in senescence accelerated mouse/prone 8 (SAMP8) hippocampal slices by inhibiting voltage-dependent calcium channels (VDCCs) and promoting Nmethyl-d-aspartate receptor (NMDA) receptors. J Ethnopharmacol. 2012; 140(2):384-90

5. Tseng YT, Chang FR, Lo YC. The Chinese herbal formula Liuwei dihuang protects dopaminergic neurons against Parkinson's toxin through enhancing antioxidative defense and preventing apoptotic death. Phytomedicine. 2014;21(5):724-33.

6. Nair SV, Zhang J, Wang Y. Ethanol extract of Liuwei Dihuang reduces weight gain and visceral fat in obese-prone CD rats fed a high-fat diet. Exp Biol Med (Maywood). 2014;239(5):552-8.

7. Perry B, Zhang J, Sun C, Saleh T, Wang Y. Liuwei dihuang lowers body weight and improves insulin and leptin sensitivity in obese rats. Evid Based Complement Alternat Med. 2012;2012:847167.

8. Shin IS, Lee MY, Ha HK, Seo CS, Shin HK. Inhibitory effect of Yukmijihwangtang, a traditional herbal formula against testosterone-induced benign prostatic hyperplasia in rats. BMC Complement Altern Med. 2012;12:48.

9. Lin L, Wang Q, Yi Y, Wang S, Qiu Z. Liuwei dihuang pills enhance the effect of western medicine in treating diabetic nephropathy: a meta-analysis of randomized controlled trials. Evid Based Complement Alternat Med. 2016; 2016:1509063.

10. Lee MS. Effect of Bojungikki-tang on the bone growth in adolescent rats. Seoul: Kyung Hee Univ; 2012.

11. Lee J, Lee S, Son J, Keum S, Leem K. Effects of Cheunggyeongsamul-tang extract on longitudinal bone growth in adolescent female rats. Kor J Herbology. 2009;24(4):149-57.

12. Leem K, Park SY, Lee DH, Boo YM, Cho KH, Lim J, Jeon H, Park HJ, Chung $\mathrm{JH}$, Kim H. Effects of Jaoga-Yukmiwon(R), a Korean herbal medicine, on chondrocyte proliferation and longitudinal bone growth in adolescent male rats. Phytother Res. 2003;17(9):1113-6.

13. Kim KB, Kim DG, Kim YH, Kim JH, Min SY, Park EJ, Baek JH, Sung HK, Yu SA, Lee SY, et al. Pediatrics of Korean medicine. Seoul: Euisungdang; 2015.

14. Jin UH, Kim DI, Lee TK, Lee DN, Kim JK, Lee IS, Kim CH. Herbal formulation, Yukmi-jihang-tang-jahage, regulates bone resorption by inhibition of phosphorylation mediated by tyrosine kinase Src and cyclooxygenase expression. J Ethnopharmacol. 2006;106(3):333-43.

15. Park BM, Soh KS, Jeong CG. Effects of Yukmiziwhang-whan on the growth of rats. Kor J Orient Prev Med Soc. 2003;7(2):23-33.

16. Xue YM, Luo R, Zhu B, Zhang Y, Pan YH, Li CZ. Effects of liuwei dihuang pills on expressions of apoptosis-related genes bcl-2 and Bax in pancreas of OLETF rats. Zhong Xi Yi Jie He Xue Bao. 2005;3(6):455-8.

17. Lui JC, Baron J. Mechanisms limiting body growth in mammals. Endocr Rev. 2011;32(3):422-40.

18. Brem G, Wanke R, Wolf E, Buchmuller T, Muller M, Brenig B, Hermanns W. Multiple consequences of human growth hormone expression in transgenic mice. Mol Biol Med. 1989;6(6):531-47.

19. Rol De Lama MA, Perez-Romero A, Tresguerres JA, Hermanussen M, Ariznavarreta C. Recombinant human growth hormone enhances tibial growth in peripubertal female rats but not in males. Eur J Endocrinol. 2000; 142(5):517-23.

20. Wong RW, Hagg U, Samaranayake L, Yuen MK, Seneviratne CJ, Kao R. Antimicrobial activity of Chinese medicine herbs against common bacteria in oral biofilm. A pilot study. Int J Oral Maxillofac Surg. 2010;39(6):599-605.

21. Duyar I, Pelin C. Body height estimation based on tibia length in different stature groups. Am J Phys Anthropol. 2003;122(1):23-7.
22. van der Eerden BC, Karperien M, Wit JM. Systemic and local regulation of the growth plate. Endocr Rev. 2003;24(6):782-801.

23. Qian Y. Key to Therapeutics of Children's Diseases. In. China; 1119.

24. Hansson LI, Stenstrom A, Thorngren KG. Skeletal deposition and toxicity of methacycline. Nature. 1968;219(5154):624-5.

25. Emons J, Chagin AS, Savendahl L, Karperien M, Wit JM. Mechanisms of growth plate maturation and epiphyseal fusion. Horm Res Paediatr. 2011; 75(6):383-91.

26. Chen G, Deng C, Li YP. TGF-beta and BMP signaling in osteoblast differentiation and bone formation. Int J Biol Sci. 2012;8(2):272-88.

27. Pizette $\mathrm{S}$, Niswander L. BMPs are required at two steps of limb chondrogenesis: formation of prechondrogenic condensations and their differentiation into chondrocytes. Dev Biol. 2000;219(2):237-49.

28. Sakou T. Bone morphogenetic proteins: from basic studies to clinical approaches. Bone. 1998:22(6):591-603.

29. Yazaki Y, Matsunaga S, Onishi T, Nagamine T, Origuchi N, Yamamoto T, Ishidou Y, Imamura T, Sakou T. Immunohistochemical localization of bone morphogenetic proteins and the receptors in epiphyseal growth plate. Anticancer Res. 1998;18(4A):2339-44.

30. Hallahan AR, Pritchard JI, Chandraratna RA, Ellenbogen RG, Geyer JR, Overland RP, Strand AD, Tapscott SJ, Olson JM. BMP-2 mediates retinoidinduced apoptosis in medulloblastoma cells through a paracrine effect. Nat Med. 2003;9(8):1033-8.

31. Wang EA, Rosen V, D'Alessandro JS, Bauduy M, Cordes P, Harada T, Israel DI, Hewick RM, Kerns KM, LaPan P, et al. Recombinant human bone morphogenetic protein induces bone formation. Proc Natl Acad Sci U S A. 1990;87(6):2220-4

32. De Luca F, Barnes KM, Uyeda JA, De-Levi S, Abad V, Palese T, Mericq V, Baron J. Regulation of growth plate chondrogenesis by bone morphogenetic protein-2. Endocrinology. 2001;142(1):430-6.

33. Klaus G, Jux C, Fernandez P, Rodriguez J, Himmele R, Mehls O. Suppression of growth plate chondrocyte proliferation by corticosteroids. Pediatr Nephrol. 2000;14(7):612-5.

34. Isaksson OG, Lindahl A, Nilsson A, Isgaard J. Mechanism of the stimulatory effect of growth hormone on longitudinal bone growth. Endocr Rev. 1987; 8(4):426-38

35. Wang J, Zhou J, Cheng CM, Kopchick JJ, Bondy CA. Evidence supporting dual, IGF--independent and IGF-I-dependent, roles for GH in promoting longitudinal bone growth. J Endocrinol. 2004;180(2):247-55.

36. Yakar S, Rosen CJ, Beamer WG, Ackert-Bicknell CL, Wu Y, Liu JL, Ooi GT, Setser J, Frystyk J, Boisclair YR, et al. Circulating levels of IGF-1 directly regulate bone growth and density. J Clin Invest. 2002;110(6):771-81.

37. Abad V, Meyers JL, Weise M, Gafni Rl, Barnes KM, Nilsson O, Bacher JD, Baron J. The role of the resting zone in growth plate chondrogenesis. Endocrinology. 2002;143(5):1851-7.

38. Farnum CE, Wilsman NJ. Determination of proliferative characteristics of growth plate chondrocytes by labeling with bromodeoxyuridine. Calcif Tissue Int. 1993;52(2):110-9.

39. Alcantara EH, Shin MY, Sohn HY, Park YM, Kim T, Lim JH, Jeong HJ, Kwon ST, Kwun IS. Diosgenin stimulates osteogenic activity by increasing bone matrix protein synthesis and bone-specific transcription factor Runx2 in osteoblastic MC3T3-E1 cells. J Nutr Biochem. 2011;22(11):1055-63.

40. Lee JW, Kobayashi Y, Nakamichi Y, Udagawa N, Takahashi N, Im NK, Seo HJ, Jeon WB, Yonezawa T, Cha BY, et al. Alisol-B, a novel phyto-steroid, suppresses the RANKL-induced osteoclast formation and prevents bone loss in mice. Biochem Pharmacol. 2010;80(3):352-61.

41. Hardin DS. Treatment of short stature and growth hormone deficiency in children with somatotropin (rDNA origin). Biologics. 2008;2(4):655-61.

42. Laron Z. Growth hormone therapy: emerging dilemmas. Pediatr Endocrinol Rev. 2011;8(4):364-73.

43. Gubitosi-Klug RA, Cuttler L. Idiopathic short stature. Endocrinol Metab Clin North Am. 2005;34(3):565-80. viii. 